\title{
Field Test Program for Long-Term Operation of a COHPAC System for Removing Mercury from Coal-Fired Flue Gas
}

\author{
Quarterly Technical Report \\ Reporting Period: January 1, 2003 - March 31, 2003
}

Principal Author

Jean Bustard
ADA Environmental Solutions, LLC 8100 SouthPark Way, Unit B
Littleton, Colorado 80120

Submitted: June 13, 2003

DOE Cooperative Agreement No.: DE-FC26-02NT41591

Report No. 41591R03 


\section{DISCLAIMER}

This technical report was prepared with the support of the U.S. Department of Energy, under Award No. DE-FC26-02NT41591. However, any opinions, findings, conclusions, or recommendations expressed herein are those of the author(s) and do not necessarily reflect the views of the DOE.

This report was prepared as an account of work sponsored by an agency of the United States Government. Neither the United States government nor any agency thereof, nor any of their employees, makes any warranty, express or implied, or assumes any legal liability or responsibility for the accuracy, completeness, or usefulness of any information, apparatus, product, or process disclosed, or represents that its use would not infringe privately owned rights. Reference herein to any specific commercial product, process, or service by trade name trademark, manufacturer, or otherwise does not necessarily constitute or imply its endorsement, recommendation, or favoring by the United States Government or any agency thereof. The views and opinions of authors expressed herein do not necessarily state or reflect those of the United States Government or any agency thereof. 


\begin{abstract}
With the Nation's coal-burning utilities facing the possibility of tighter controls on mercury pollutants, the U.S. Department of Energy is funding projects that could offer power plant operators better ways to reduce these emissions at much lower costs. Sorbent injection technology represents one of the simplest and most mature approaches to controlling mercury emissions from coal-fired boilers. It involves injecting a solid material such as powdered activated carbon into the flue gas. The gas phase mercury in the flue gas contacts the sorbent and attaches to its surface. The sorbent with the mercury attached is then collected by the existing particle control device along with the other solid material, primarily fly ash.
\end{abstract}

During 2001 ADA Environmental Solutions (ADA-ES) conducted a full-scale demonstration of sorbent-based mercury control technology at the Alabama Power E.C. Gaston Station (Wilsonville, AL). This unit burns a low-sulfur bituminous coal and uses a hot-side electrostatic precipitator (ESP) in combination with a COHPAC baghouse to collect fly ash. The majority of the fly ash is collected in the ESP with the residual being collected in the COHPAC baghouse. Activated carbon was injected between the ESP and COHPAC units to collect the mercury.

Short-term mercury removal levels in excess of $90 \%$ were achieved using the COHPAC unit. The test also showed that activated carbon was effective on removing both forms of mercury, elemental and oxidized. However, a great deal of additional testing is required to further characterize the capabilities and limitations of this technology relative to use with baghouse systems such as COHPAC. It is important to determine performance over an extended period of time to fully assess all operational parameters.

The project described in this report focuses on fully demonstrating sorbent injection technology at a coal-fired power generating plant that is equipped with a COHPAC system. The overall objective is to evaluate the long term effects of sorbent injection on mercury capture and COHPAC performance. The work is being done on $1 / 2$ of the gas stream at Alabama Power's Plant Gaston Unit 3 (nominally $135 \mathrm{MW}$ ). Data from the testing will be used to determine:

1. Is sorbent injection into a high air-to-cloth ratio baghouse a viable, long term approach for mercury control; and

2. Design criteria and costs for new baghouse/sorbent injection systems that will use a similar, polishing baghouse (TOXECON) approach. 


\section{TABLE OF CONTENTS}

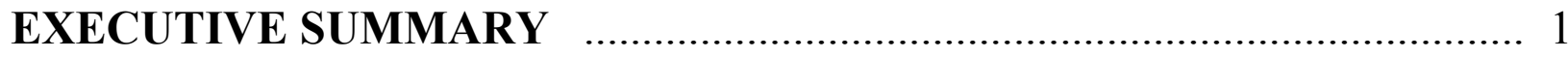

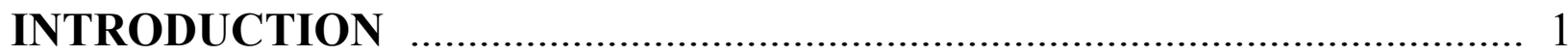

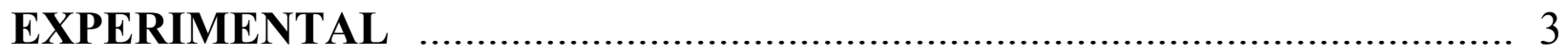

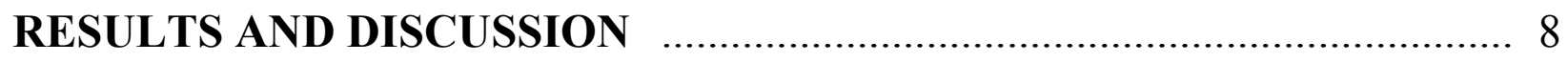

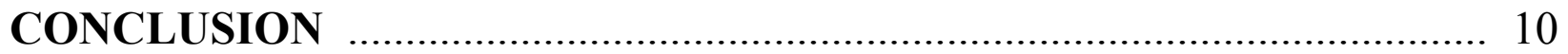

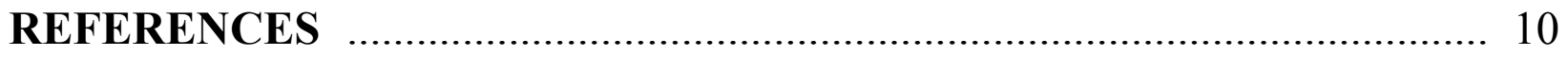

LIST OF ACRONYMS AND ABBREVIATIONS ................................. 11 


\section{LIST OF GRAPHICAL MATERIALS}

There are no graphical materials included in this report.

\section{EXECUTIVE SUMMARY}

ADA-ES began work on a Cooperative Agreement with the Department of Energy in September 2002 to fully evaluate activated carbon injection (ACI) in conjunction with a high-ratio baghouse (COHPAC) for mercury control. The work is being conducted at Alabama Power Company's Plant Gaston. During the two-year project, a powdered activated carbon injection system will be installed and tested at the plant for a continuous 1-year period of time. ADA-ES is responsible for managing the project including engineering; testing, economic analysis, and information transfer functions.

During the third reporting quarter, January through March 2003, progress on the project has been made in the following areas:

- Carbon injection equipment installation was completed.

- A mercury analyzer was installed and is operational.

- The baseline phase of the test program began.

- Manual flue gas measurements of mercury were performed.

- COHPAC performance was reviewed.

- A manual inspection of the bags was made.

- A spare set of filter bags was ordered and should arrive on site by the end of June.

- The project test plan was reviewed and finalized.

\section{INTRODUCTION}

Cooperative Agreement No. DE-FC26-02NT41591 was awarded to ADA-ES to demonstrate Activated Carbon Injection (ACI) technology on a coal-fired boiler equipped with a COHPAC baghouse. Under the contract, ADA-ES is working in partnership with DOE/NETL, Alabama Power and EPRI.

A detailed topical report will be prepared at the end of the 1-year test period. Quarterly reports will be used to provide project overviews and technology transfer information.

\section{Team Members}

This program is made possible by significant cost share support from the following companies:

- EPRI

- Southern Company/Alabama Power 
- Hamon Research-Cottrell

- Alleghany Power

- Ontario Power Generation

- TVA

- Arch Coal Inc.

- ADA-ES

A group of highly qualified individuals and companies were assembled to implement this program. Project team members include:

- ADA-ES

- Southern Research Institute

- Grubb Filtration Testing Services

- Reaction Engineering International

A change in the team members status this period is that Sharon Sjostrom, formally with EMC Engineering, has joined ADA-ES as a full-time employee. 


\section{EXPERIMENTAL}

\section{Activated Carbon Injection Equipment}

The activated carbon injection equipment was installed and field-tested. The major tasks included:

- Engineering and installation of foundation

- Shipping and installation of silo and feeders

- Design, fabrication and installation of hoses and distribution manifolds

- String and terminate electrical and communications cables to skid, analyzers, analyzer shed and extraction locations.

A scope-of work for the mechanical portion was developed and sent out for bid. The work was awarded to G\&R Plant Services. The electrical scope-of-work was awarded to the plant electrical contractor, Canterbury Electric.

Figure 1 is a photograph of the excavation and supporting rebar just before concrete was poured for the foundation. Figure 2 shows the carbon silo being lifted off the flat bed truck as it was positioned on the foundation.

A new distribution manifold (splitter) and injection lances were designed and fabricated. The splitter is a proprietary annulus design, which has proven to be very effective on the even distribution of the fine and abrasive activated carbon. The splitter distributes carbon to six injection lances (three in each duct). The lances are made from 1-inch carbon steel pipe, are $6 \mathrm{ft}$ in length and have a $45^{\circ}$ beveled edge at the nozzle end to direct the carbon co-current with flow.

The plant provided a load signal to the skid control panel so that carbon can be injected proportional to load. An analysis of boiler load versus flue gas flow was performed and an algorithm that relates load to flow was developed. Using this approach, the system is now programmed to maintain the target injection concentration (lbs/Mmacf) as load varies. 


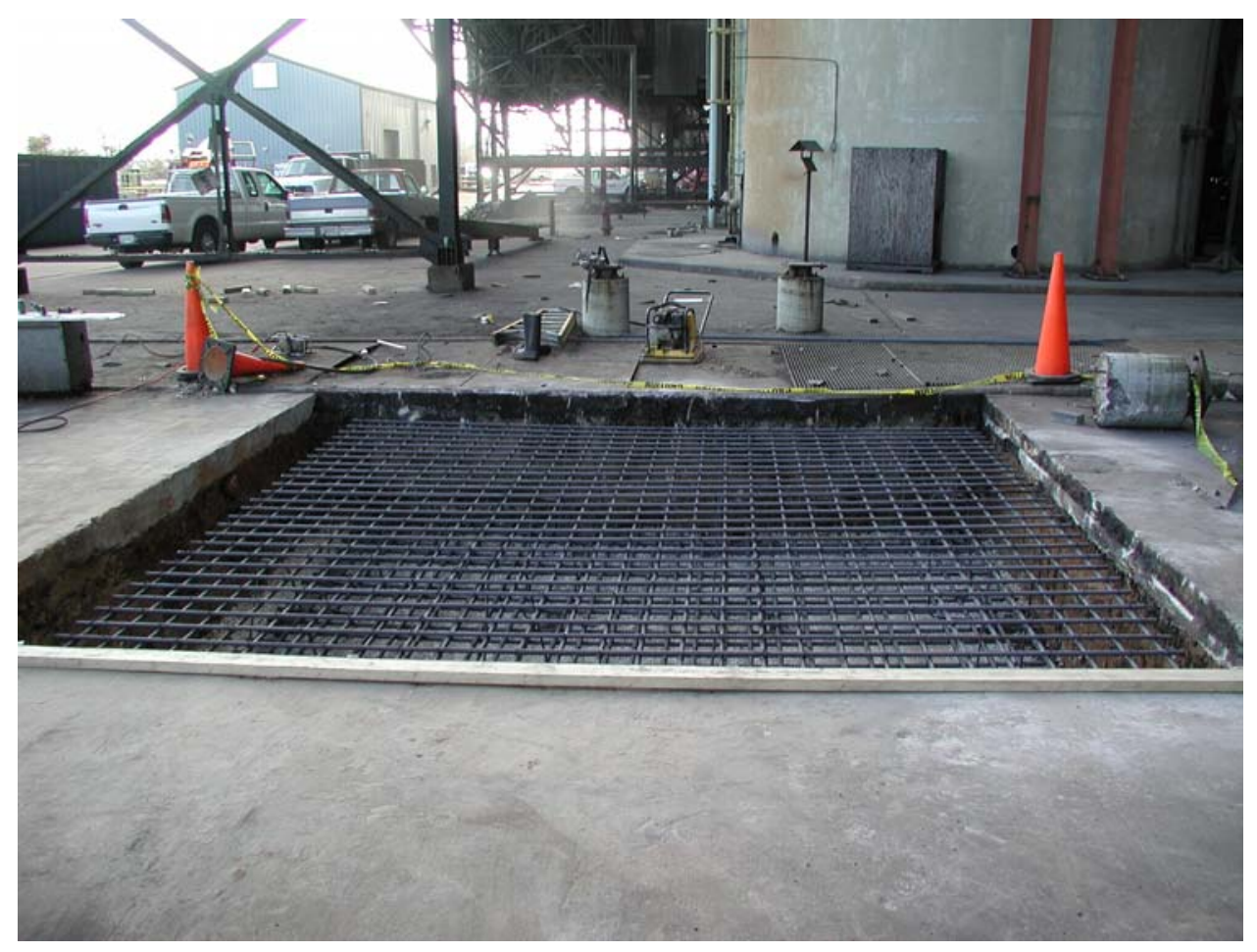

Figure 1. Foundation excavation and supporting rebar just prior to pouring concrete, Gaston January 2003.

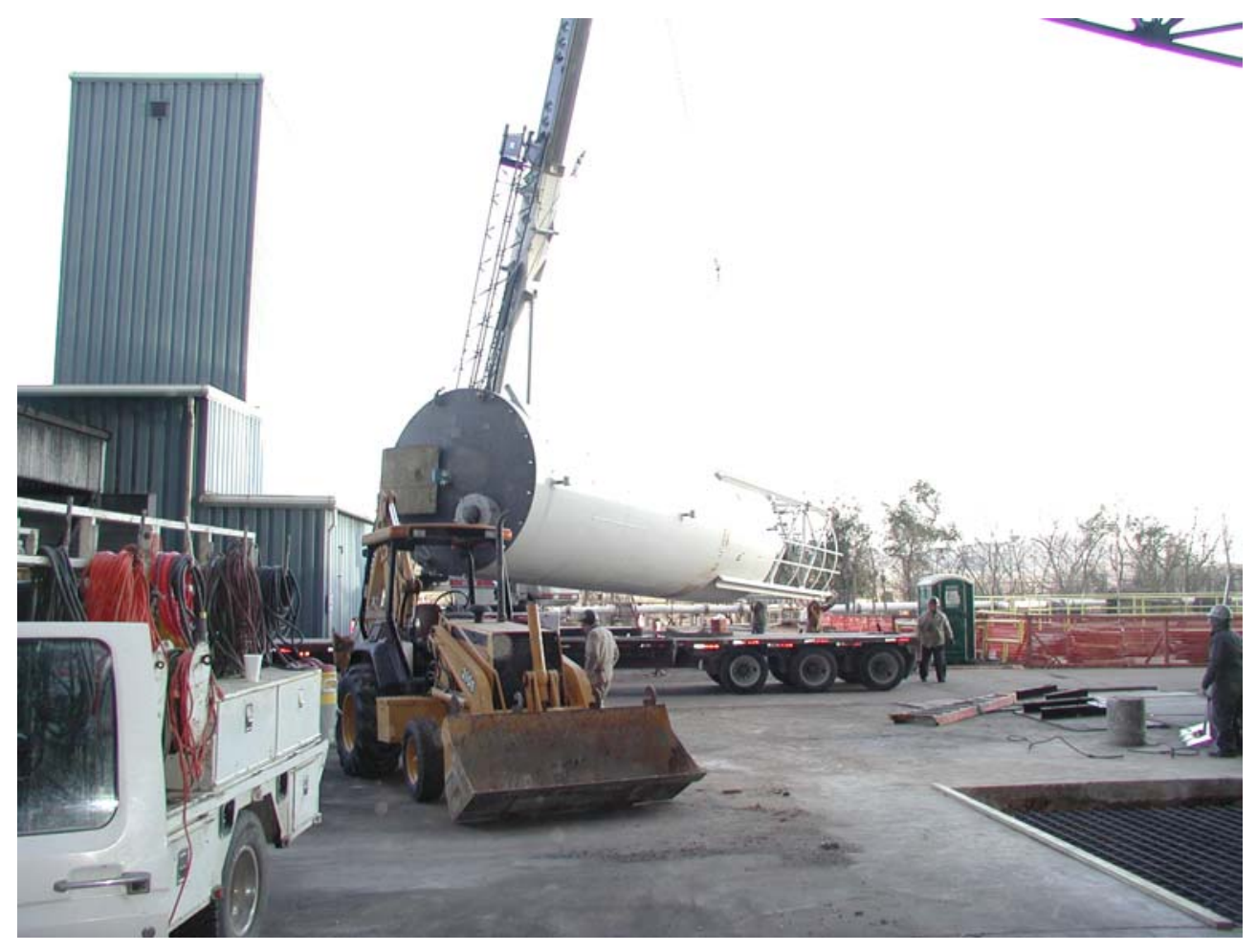

Figure 2. Lifting the carbon silo from the truck before setting on the foundation, Gaston January 2003. 


\section{Mercury Analyzer}

The new mercury analyzer is now operating and measuring total vapor phase mercury at the inlet and outlet of the COHPAC. One detector is used to measure mercury at the inlet and outlet of COHPAC. Measurements alternate between inlet and outlet, with about 15 minutes of data taken at one location before switching to the other. Data has been collected on and off for the first couple of weeks of operation. Most start-up issues have been resolved and on-site personnel are performing daily calibrations and routine maintenance. Analyzer operation performance is acceptable. Over the next few weeks and months, some changes will be made to make incremental improvements that will reduce operation and maintenance requirements, but the overall system design will not changed. The current schedule is to run the analyzers 24 hours a day during the week, and shut down over the weekend. This may change as operation and maintenance activities are streamlined.

There are six primary components of the mercury analyzer system. A brief description follows:

1. Sample extraction - Mercury is present in flue gas as both a particulate and in vapor phase. The analyzer we are using measures only vapor phase mercury. Particulate must be removed before the gas sample enters the measurement chamber. This program uses an extraction probe provided by Apogee Scientific. Particulate is separated from the flue gas using an inertial separation filter.

2. Conversion/speciation - Vapor phase mercury exists in the flue gas as either elemental $\left(\mathrm{Hg}^{0}\right)$ or oxidized $\left(\mathrm{Hg}^{2+}\right)$. Because mercury detectors measure only elemental mercury, the flue gas sample must pass through a conversion unit so that all vapor phase species of the mercury are converted to elemental mercury. A wet chemistry based conversion system is used. The sample gas passes through a set of impingers before entering a chiller to drop out moisture. Figure 3 is a photo of a set of impingers on one of the extraction probes at Gaston.

3. Sample transport - The sample is transported over 100 feet from the extraction probe to the mercury detector in the CEM shed located at the hopper level. The issues with transport at this site are high pressure drop and the need for heated, Teflon lines. An evaluation will be conducted to increase the tube size from $1 / 4$ " to $3 / 8$ " to reduce pressure loss.

4. Measurement (detector) - The measurement method is Cold Vapor Atomic Adsorption technology. This has been proven to be a very effective method as long as a conditioned, moisture-free sample is delivered to the analyzer. Figure 4 is a picture of the detector installed in the shed at Gaston. The sample transport line can also be seen in the photograph.

5. Calibration - To insure reliability and accuracy of all the components, the instrument must be calibrated at a minimum of once a day. Currently the analyzer is 
calibrated by injecting a know amount of elemental mercury upstream of the impingers.

6. Data management - Data is downloaded daily from the detector data logger. Data is then entered into spreadsheets and analyzed, averaged and plotted. These same spreadsheets are used to troubleshoot and check detector operation. Efforts to automate and standardize this process are underway, which will save data analysis time over the length of the project.

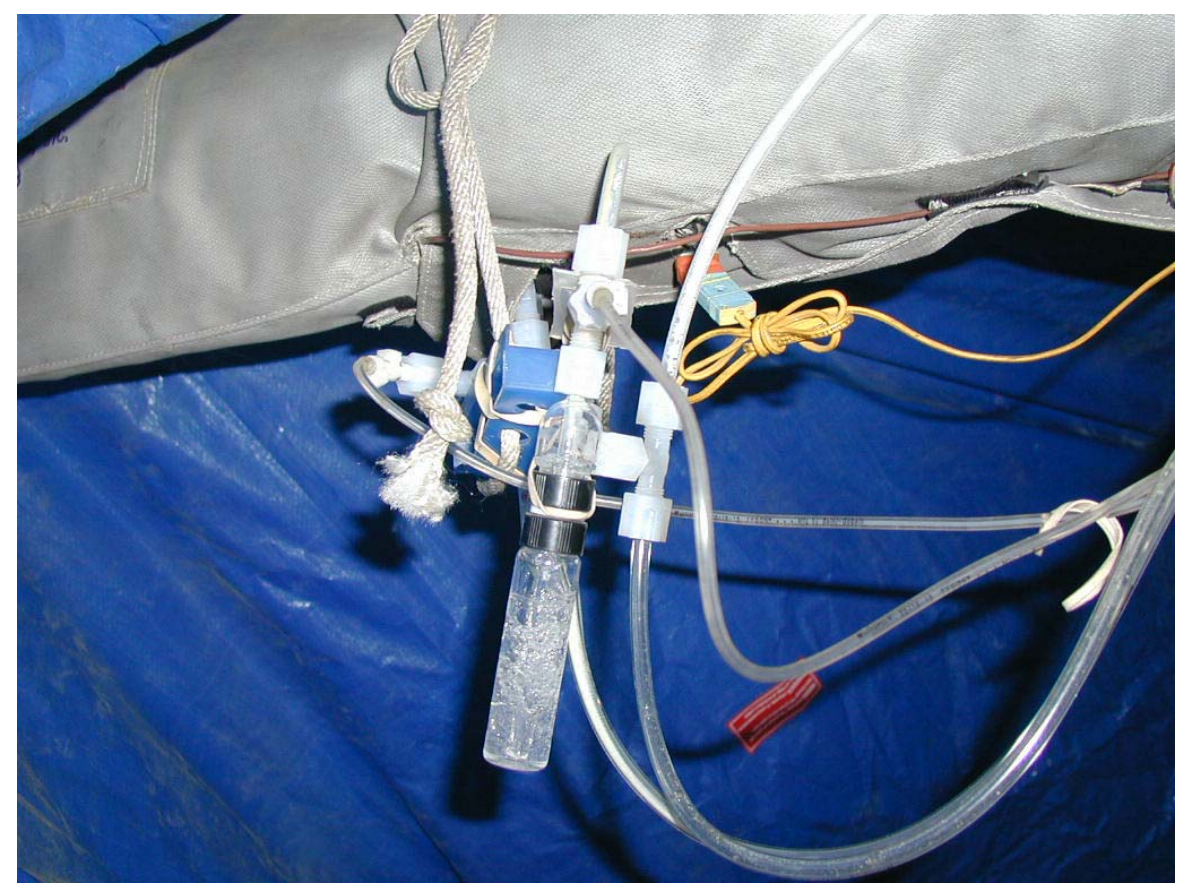

Figure 3. Impingers used to convert vapor phase species of mercury to elemental mercury at Gaston. 


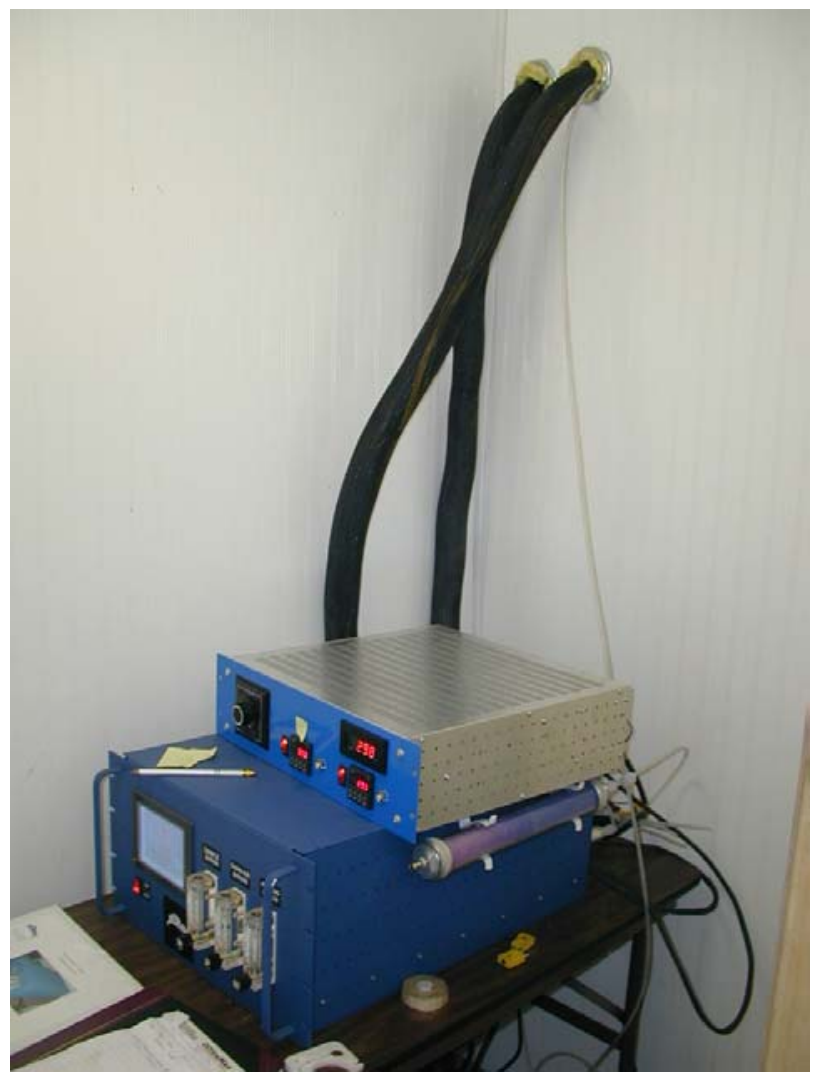

Figure 4. Mercury detector installed at Gaston.

A complete set of spare bags has been ordered, and should be on site by the end of June. Grubb Filtration has approved the top cuff materials, and the fit in the tube sheet hole. There are some unacceptable manufacturing techniques and assembly of the top cuff to the bag, which are being addressed and corrections will be made. The bag manufacturer, for approval, should submit the full size sample bag by mid-May. 


\section{RESULTS AND DISCUSSION}

\section{Baseline Tests}

Unit 3 came online in mid-March after a several week outage. During this outage the compartments were inspected and the hot-side electrostatic precipitator (ESP's) was washed. The ESP's are washed at least yearly to remove sodium depleted ash layers that can cause performance degradation.

The baseline tests officially started on March 24, when continuous mercury measurements with the analyzer began. The baseline period was planned to gather operating performance of the COHPAC baghouse and measure mercury at the inlet and outlet of COHPAC under normal operating conditions, just prior to starting carbon injection. Also during this period ash and coal samples were collected.

\section{COHPAC Performance}

During an outage on Unit 3 in March, Southern Research Institute (Ken Cushing) and Grubb Filtration Testing Services (Theron Grubb) were on-site to do a visual inspection of the bags and to measure in-situ drag of the bags. In-situ drag measurements provide an indication of the pressured drop caused by the bag and the residual dustcake (flyash that remains on the bag following normal cleaning conditions).

\section{Bag Inspection}

Prior to taking the baghouse offline, a fluorescent powder (Visolite ${ }^{\mathrm{TM}}$ ) was injected into the four compartments on Unit 3 baghouse (two compartments each on A- and B-side). The compartments were then opened and the top of the tubesheet inspected with a black light. Areas where the fluorescent powder could be seen on the tubesheet or inside the bags were identified and a closer inspection made. This is a technique used in the industry to identify leaking bags and the fluorescent powder can be bought commercially from bag suppliers.

Ken Cushing documented findings from this inspection, "Very few problems were observed. There are four bag bundles in the B-side baghouse, 3B10, 3B11, 3B20, 3B21. There were no bag related problems in 3B10 or 3B11. There were three failed bags in 3B20 and two bags had slipped off the cages in 3B21. The bags were replaced with 2.7 denier PPS bags."

In addition to the two bags replaced because the bags had slipped of the cages, a third new bag (for a total of three) was installed in 3B21. Three new bags were also installed in bag bundle 3B20. These new bags will be removed at the end of the test and used to compare bag strength and residual drag of with that of the older bags.

Note - each bag bundle can hold up to 544 bags. There are two bundles in each compartment. Note - On B-side the front bag bundles (3B10 and 3B20) of each compartment have been in service of 28 months. The back bundles (3B11 and 3B21) have been in service for 15 months. 


\section{Drag Measurements}

Residual drag measurements were performed with the compartment off line using an in-situ drag measurement device designed for EPRI. The average measured drag of the four bundles varied between 0.31 and 0.39 inches $\mathrm{H}_{2} \mathrm{O} / \mathrm{ft} / \mathrm{min}$. These values are comparable to historical data. Experience shows that in-situ drag values are acceptable when less than 0.50 inches $\mathrm{H}_{2} \mathrm{O} / \mathrm{ft} / \mathrm{min}$. Values higher than this often result in high cleaning frequencies.

\section{COHPAC Performance}

At Gaston, the primary variable used to track COHPAC performance is cleaning frequency. The cleaning logic is set to begin a clean at a specified pressure drop/drag set-point.

There was a noticeable change in cleaning frequency before and after the spring outage. Prior to the outage average cleaning frequency varied between 1 and 2 pulses per bag per hour. After the outage, the average cleaning frequency was often above two, with periods of continuous cleaning (4 pulses per bag per hour). This presents a problem because adding carbon to the baghouse would increase cleaning frequency further. It is believed that burning certain coals causes the high cleaning frequency. This cause of higher cleaning frequency is being investigated. Figure 5 presents Unit 3 boiler load and Unit 3B-cleaning frequency in pulses/bag/hour before and after the outage. This graph shows that cleaning frequency is higher after the outage, with periods of continuous cleaning (4 pulse/bag/hour). This was especially surprising since the ESP's had just washed and they should have been in the best operating condition.

Gaston Unit 3 Baghouse (B Casing) Performance Data

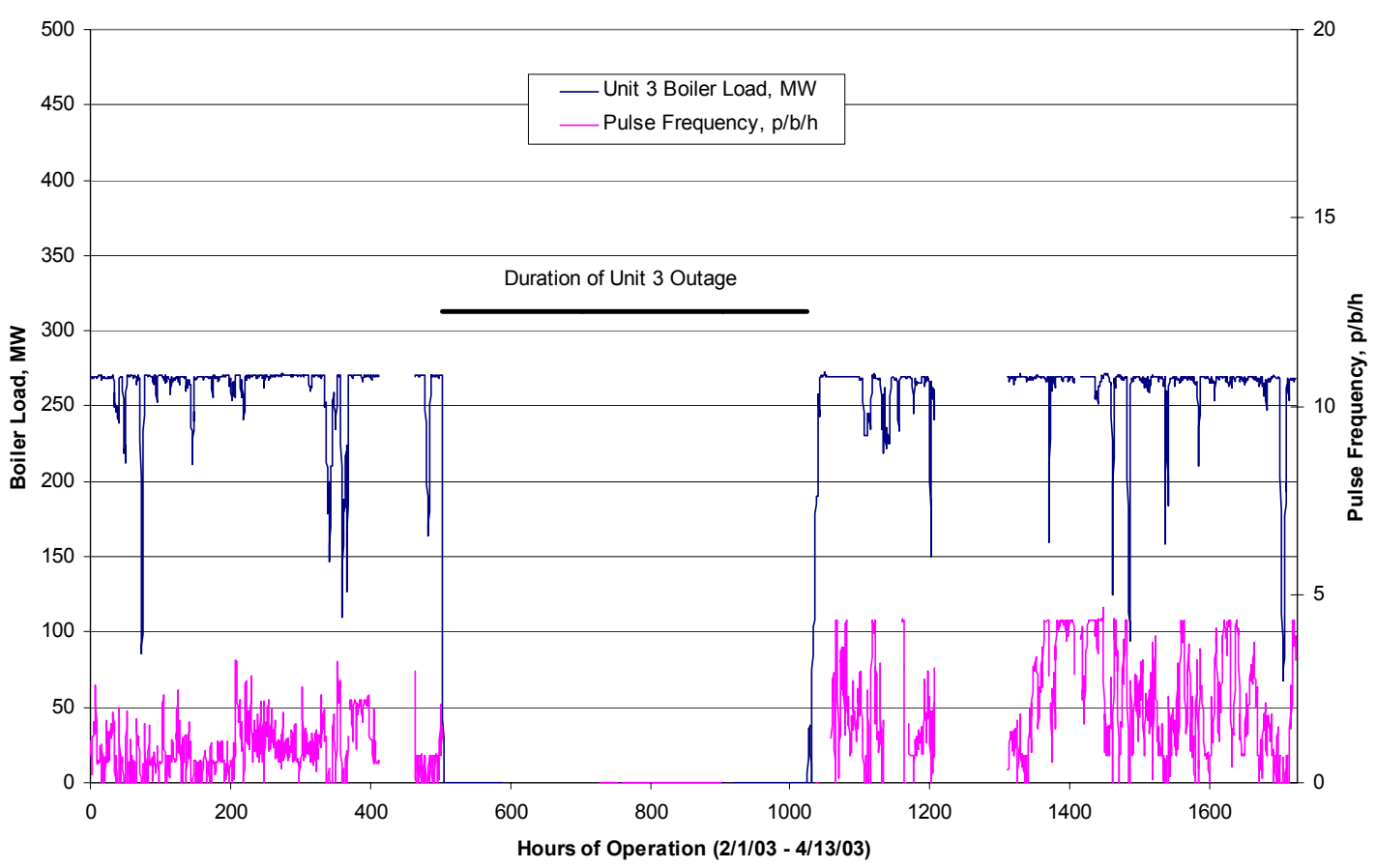

Figure 5. Unit 3B baghouse cleaning frequency and boiler load before and after March 2003 outage. 


\section{Mercury Measurements}

Weston Solutions, Inc conducted Ontario Hydro measurements for total mercury on April 1, 2, and 3. Measurements for $\mathrm{HCl}$ and for multi-metals (Method 29 at outlet only) were also made. Results from these tests are expected by the end of May.

Operation during this time was intermittent due to a factory problem with the on-board computer. Mercury measurements will be presented for the baseline period in the next quarterly report.

\section{Ash and Coal Measurements}

During baseline testing, coal samples were collected daily during the week and ash samples were collected periodically from both the A- and B-side COHPAC hoppers and from the hot-side ESP hopper.

\section{Filter Bags}

A complete set of spare bags has been ordered, and should be on site by the end of June. Grubb Filtration Testing Services (GFTS) worked with plant personnel on updating the existing bag specification for the new 7-denier fabric. Hamon Research Cottrell's purchasing department assisted with issuance of the Request for Quote (RFQ) and provided a review of the bids. The job order was awarded to Midwesco Filter Resources.

Grubb Filtration has approved the top cuff materials, and the fit in the tube sheet hole. There are some unacceptable manufacturing techniques and assembly of the top cuff to the bag, which are being addressed and corrections will be made. The bag manufacturer, for approval, should submit the full size sample bag by mid-May.

\section{CONCLUSION}

None this reporting period.

\section{REFERENCES}

None this reporting period. 


\section{LIST OF ACRONYMS AND ABBREVIATIONS}

$\begin{array}{ll}\text { ACI } & \text { Activated Carbon Injection } \\ \text { APC } & \text { Alabama Power Company } \\ \text { COHPAC } & \text { Compact Hybrid Particulate Collector } \\ \text { DOE } & \text { Department of Energy } \\ \text { ESP } & \text { Electrostatic Precipitator } \\ \text { kW } & \text { Kilo Watts } \\ \text { MW } & \text { Mega Watts } \\ \text { NETL } & \text { National Energy Technology Laboratory } \\ \text { O\&M } & \text { Operating and Maintenance } \\ \text { S-CEM } & \text { Semi-Continuous Emission Monitor } \\ \text { TCLP } & \text { Toxicity Characteristic Leaching Procedure }\end{array}$

